\title{
Neuromonitoreo y protección cerebral en cirugía cardiovascular
}

\author{
Romero Santana GM. ${ }^{1}$, Castro Aguilar Aguila M. ${ }^{1}$, Espinosa Gutiérrez JC. ${ }^{1}$, Gómez Leandro II. ${ }^{1}$ \\ 1 Centro Médico Nacional La Raza, Ciudad de México, México.
}

Las cardiopatías isquémicas y valvulares estan aumentando a nivel mundial entre un 15 al 20\% anual, la cirugía cardiovascular en la cual se deben implementar medidas de vigilancia y protección a nivel neurológico con el fin de valorar la función y perfusión, ya que la presencia de eventos neurológicos posterior a cirugía cardiaca tiene una incidencia del $6 \%$ los cual refleja un aumento de la morbimortalidad hasta en un $21 \%$. Las necesidades del monitoreo cada vez son mayores, el impacto sobre los órganos vitales puede aumentar o disminuir la mortalidad; la única manera de valorarlo es por medio de equipos de diferentes tecnologías. Idealmente para valorar a nivel neurofisiológico el monitoreo es no invasivo continuo y rápido detectando de manera mas rápida y confiable cambios en la perfusión y en la función cerebral. Actualmente se utilizan: electroencefalogramas (EEG) y los potenciales evocados que proveen información acerca de la función cerebral así como la espectroscopia infrarroja regional (NIRS), el Doppler transcraneal y el uso del bulbo yugular para valorar la perfusión cerebral. Los agentes anestésicos y la profundidad anestésica afectan el flujo sanguíneo cerebral y el consumo metabólico de oxígeno. Se encuentran diversas estrategias para disminuir los posibles daños a nivel cerebral como reducir la demanda de oxígeno por medio de hipotermia, mantener los sustratos para un equilibrio en perfusión y función cerebral como glucosa, oxígeno, aminoácidos, soluciones buffer que optimizan el metabolismo celular, reducción de la sobrecarga de calcio y la reducción del edema con soluciones hiperosmolares como manitol, cloruro de potasio y glucosa; otros mecanismos utilizados son medicamentos como los opioides que reducen ligeramente ambos parámetros flujo sanguíneo y consumo metabólico, manteniendo intacta la autorregulación cerebral.

Resultados: Describir la protección cerebral vigilada con neuromonitoreo en cirugía cardiovascular y asociarla con eventos neurológicos postquirúrgicos. Se realizó un estudio descriptivo, prospectivo, transversal, sin presencia de grupo control sin ceguedad de la aplicación y evaluación, se incluyendo pacientes entre 45 a 70 años de edad sometidos a cirugía cardiaca sin antecedentes de evento vascular cerebral o déficit neurológico, con un cálculo con intervalo de confianza del $95 \%$ y valor b 0,05 , poder estadístico de $95 \%$.

Conclusión: El neuromonitoreo aplicado en el Hospital General de La Raza promueve una baja prevalencia de eventos neurológicos monitorizados del $8,1 \%$ con la presencia de $4,8 \%$ de eventos neurológicos siendo menor por la protección neurológica dentro de cirugías cardiaca de manera oportuna y optima.

https://doi.org/10.25237/congresoclasa2019.22 